\title{
MODELLING OF THE COUPLED BEAM-PIEZOELECTRIC MATERIAL WITH HYSTERESIS NON-LINERITY EFFECT
}

\author{
Mohd Hafiz Abdul Satar and Ahmad Zhafran Ahmad Mazlan* \\ TheVibrationLab, School of Mechanical Engineering, Engineering Campus, Universiti Sains \\ Malaysia, Penang \\ *Email: zhafran@usm.my
}

\begin{abstract}
Hysteresis is one of the non-linearity characteristics of the piezoelectric material. This characteristic is important to be characterized since it can affect the performance of the piezoelectric material as sensor or actuator in many applications. In this study, the model of the coupled aluminium beam with single piezoelectric patch material is constructed to investigate the hysteresis effect of the piezoelectric material to the whole beam structure. A P-876 DuraAct ${ }^{\mathrm{TM}}$ type piezoelectric patch material is used in modelling of the piezoelectric actuator. Firstly, the modal analysis of the coupled beam-piezoelectric actuator is determined to get the natural frequencies and mode shapes. Then, the piezoelectric patch material is investigated in terms of actuator by given a sinusoidal voltage excitation and output in terms of deflection, stress and strain of the piezoelectric actuator are investigated. From the results, it is clear that, the coupled beampiezoelectric material is affected by the hysteresis of the piezoelectric material and the natural frequencies of the beam structure. This characteristic is important for the piezoelectric actuator manufacturer and by providing the correction algorithm, it can improve the performance of the piezoelectric actuator for many applications.
\end{abstract}

Keywords: Hysteresis, coupled beam-piezoelectric material, modal analysis, voltage excitation, deflection.

\section{INTRODUCTION}

Hysteresis is one of non-linear characteristic of the piezoelectric. It has caused 'lag' between mechanical and electric relationship. The hysteresis loop itself contain more or less the information of magnitude response and phase angle produced by a periodic signal with constant amplitude [1]. For the application of piezoelectric, it has restrained the piezoelectric to act as an actuator, sensor or both.

From previous study, hysteresis is observed as a rate-dependent inherent characteristic and more likely to occur at high operating frequencies [2]. In term of error contribution to piezoelectric performance, it caused up to $15 \%$ of tracking error to the total displacement range and will give disadvantage for any application [3].

In recent studies, modeling and dynamic response of the piezoelectric has been widely using finite element method (FEM). This method includes modal analysis, harmonic response and transient analysis that allow further understanding between mechanical systems and vibration effects [4].

In [5], the FEM method also has been used in characterization of double piezoelectric material as actuator. The piezoelectric is significantly capable to demonstrate as an actuator and 
output acceleration is increased when the voltage increased. This article also shows a good indicator whereby the output acceleration is maximum when close to the natural frequency.

\section{METHODOLOGY}

\section{Modal Analysis of the Coupled Beam-Piezoelectric Material}

Modal analysis of the coupled beam-piezoelectric is performed to determine the vibration characteristic such as natural frequencies and mode shapes [6]. The modelling of the beam structure is constructed as shown in Figure 1. The material properties of the beam are selected from the engineering data library and assigned with aluminum alloy as shown in Table 1 . The ceramic type piezoelectric material used in this structural analysis is PIC255 and more importantly, the piezoelectric properties are directional-independent, or the pooling direction is consistent based on element coordinate system and material definition. In this analysis, the pooling direction is set in $z$-direction and data properties is summarized in Table 2.



Figure 1: Model of coupled beam-piezoelectric [5].

Table 1: Aluminum alloy properties [5].

\begin{tabular}{|l|l|}
\hline \multicolumn{1}{|c|}{ Property } & \multicolumn{1}{c|}{ Value } \\
\hline Density & $2770 \mathrm{~kg} / \mathrm{m}^{3}$ \\
\hline Isotropic elasticity: & \\
1. Young's modulus, $\mathrm{E}$ & $71000 \mathrm{MPa}$ \\
2. Poisson's ratio, $v$ & 0.33 \\
3. Bulk modulus, $\mathrm{E}_{\mathrm{b}}$ & $69600 \mathrm{MPa}$ \\
4. Shear modulus, $\mathrm{E}_{\mathrm{a}}$ & $26692 \mathrm{MPa}$ \\
\hline
\end{tabular}

Table 2: Piezoelectric patch properties.

\begin{tabular}{|c|c|c|c|c|c|c|c|}
\hline Property & \multicolumn{7}{|c|}{ Value } \\
\hline Density, $\rho$ & \multicolumn{7}{|c|}{$7800 \mathrm{~kg} / \mathrm{m} 3$} \\
\hline & {$\left[\begin{array}{c}12300 \\
0 \\
0 \\
0 \\
0 \\
0\end{array}\right.$} & $\begin{array}{c}7025 \\
9711 \\
0 \\
0 \\
0 \\
0\end{array}$ & $\begin{array}{c}7670 \\
7025 \\
12300 \\
0 \\
0 \\
0\end{array}$ & $\begin{array}{c}0 \\
0 \\
0 \\
2226 \\
0 \\
0\end{array}$ & $\begin{array}{c}0 \\
0 \\
0 \\
0 \\
2226 \\
0\end{array}$ & $\left.\begin{array}{c}0 \\
0 \\
0 \\
0 \\
0 \\
2315\end{array}\right]$ & $\times 10^{10} \mathrm{~Pa}$ \\
\hline Piezoelectric constant, $e$ & & & {$\left[\begin{array}{c}0 \\
0 \\
0 \\
1190 \\
0 \\
0\end{array}\right.$} & $\begin{array}{l}-715 \\
1370 \\
-715 \\
0 \\
0 \\
0\end{array}$ & $\left.\begin{array}{c}0 \\
0 \\
0 \\
0 \\
1190 \\
0\end{array}\right]$ & $N / V m$ & \\
\hline Permittivity constant, $\frac{\varepsilon}{\varepsilon_{0}}$ & & & {$\left[\begin{array}{c}1649 \\
0 \\
0\end{array}\right.$} & $\begin{array}{c}0 \\
1750 \\
0\end{array}$ & $\left.\begin{array}{c}0 \\
0 \\
1649\end{array}\right]$ & & \\
\hline
\end{tabular}




\section{Piezoelectric Patch Material Characterization}

In the analysis setting, the time step used is $0.00025 \mathrm{~s}$ with step end time of $0.1 \mathrm{~s}$. For the piezoelectric actuator patch, the piezoelectric body is defined as MEMs body. The voltage input function is calculated from the equation below:

$V=V_{o} \sin (2 \pi f t)$

Where $V_{0}=100 \sim 500 \mathrm{~V}$ and $f=100 \sim 500 \mathrm{~Hz}$. For the results, a probe will be used and located at end of the beam. This will show the result (i.e. deformation, velocity and acceleration) varies over time and hysteresis data is collected from range of $0.02 \mathrm{~s}$ to $0.035 \mathrm{~s}$. In addition, the solution result of the acceleration is set in $z$-direction due to beam structure is displaced in this direction.

\section{RESULTS AND DISCUSSION}

\section{Modal Analysis and Harmonic Response of the Coupled Beam-Piezoelectric Material}

The results of natural frequencies and mode shapes of the coupled beam-piezoelectric are shown in Figure 2. The natural frequencies are ranges from 0 to $500 \mathrm{~Hz}$ and four mode shapes obtained as shown in Figure 2. The natural frequencies are $16.61 \mathrm{~Hz}, 157.3 \mathrm{~Hz}$ and $546.4 \mathrm{~Hz}$ as first bending, second and third bending respectively. Whereas, the third mode shape is at $179.2 \mathrm{~Hz}$ with first torsional. The frequency response function (FRF) graph is obtained in harmonic response analysis. Figure 3 shows the FRF of acceleration at $z$-axis direction. Its shows that the bending modes at first and second modes are significantly affected the beam compared to torsion (third mode). Nevertheless, the pattern shows the acceleration tend to decrease as distance from frequencies at $16.61 \mathrm{~Hz}$ and $179.2 \mathrm{~Hz}$.

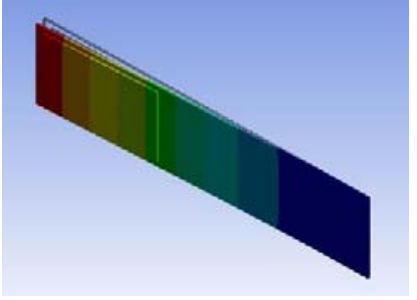

First Mode $(16.61 \mathrm{~Hz})$

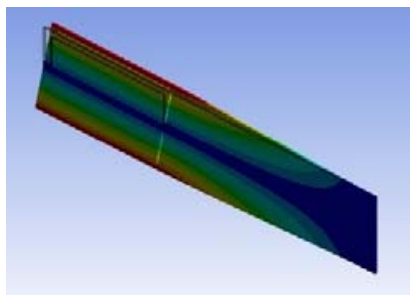

Third Mode (179.2 Hz)

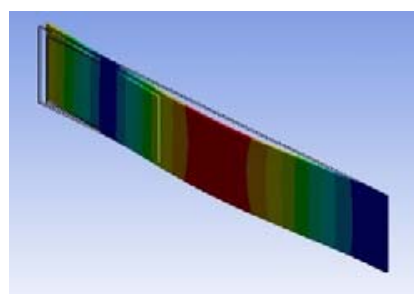

Second Mode (157.3 Hz)

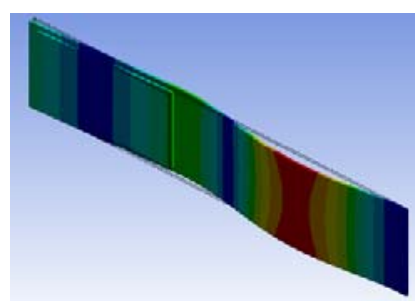

Fourth Mode (546.4 Hz)

Figure 2: Mode shapes of beam structure. 


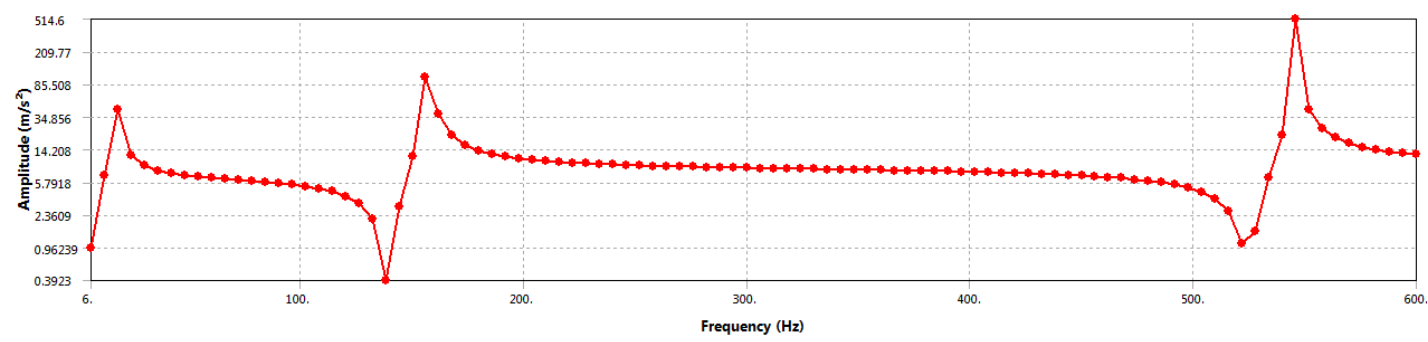

Figure 3: FRF of acceleration of the beam structure.

\section{Piezoelectric Patch Material Characteristics with Hysteresis Effects}

Figure 4 shows the illustration of the displacement, stress and strain analyses occurred in coupled beam-piezoelectric structure. In one complete cycle analysis, there are always a peak and a through point and each of this point has different stress and strain contours. At peak point in Figure 5(a) and Figure 6(a), the highest stress occurred around the piezoelectric mounted to the beam with $9.77 \mathrm{MPa}$ and strain tend to elongate at fixed end of beam with $4.49 \times 10^{-6}$. For through point in Figure 5(b), it has small stress contour with only of $0.243 \mathrm{MPa}$. But differently for strain, it occurred in middle region of beam structure and small strain contour of $2.44 \times 10^{-5}$, as shown in Figure 6(b).

(a)



(b)



Figure 4: Deflection of beam structure at (a) peak point (b) through point.

(a)

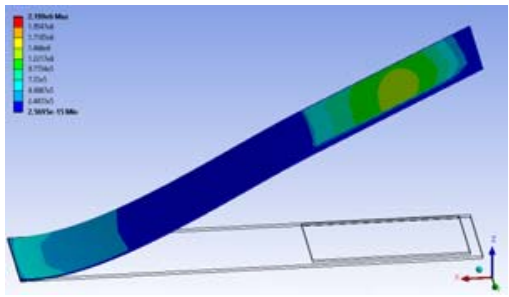

Figure 5: Stress contour at (a) peak point (b) through point.

(a)

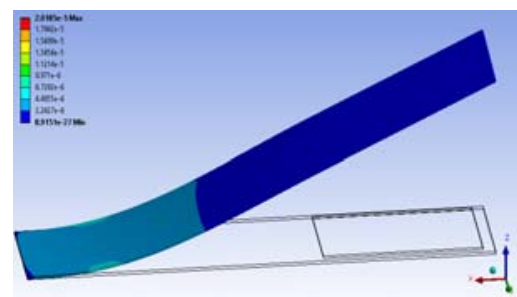

(b)

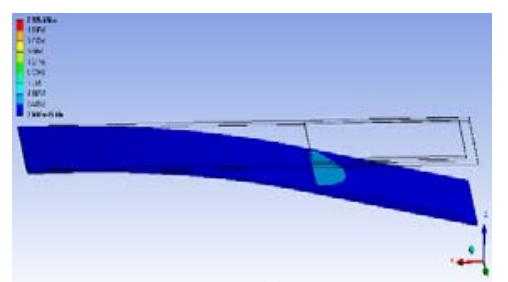

(b)

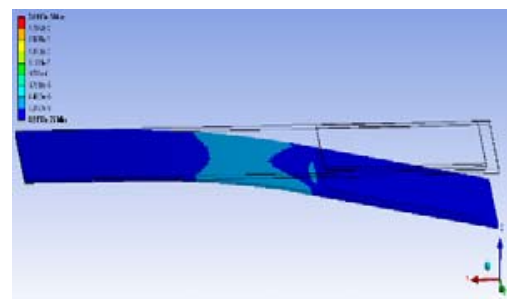

Figure 6: Strain contour at (a) peak point (b) through point. 
For the transient analysis, the results obtained from ANSYS is tabulated and plotted as in Figure 7, the graphs of output acceleration against input voltage for one complete cycle of the piezoelectric patch actuator at different operation frequencies and voltages. In Figure 7(a), it is found that the hysteresis area at frequency of $100 \mathrm{~Hz}$ is getting larger when the input voltage increased. To be noticed, the hysteresis area is increased consistently except at negative voltage input voltage for $500 \mathrm{~V}$.

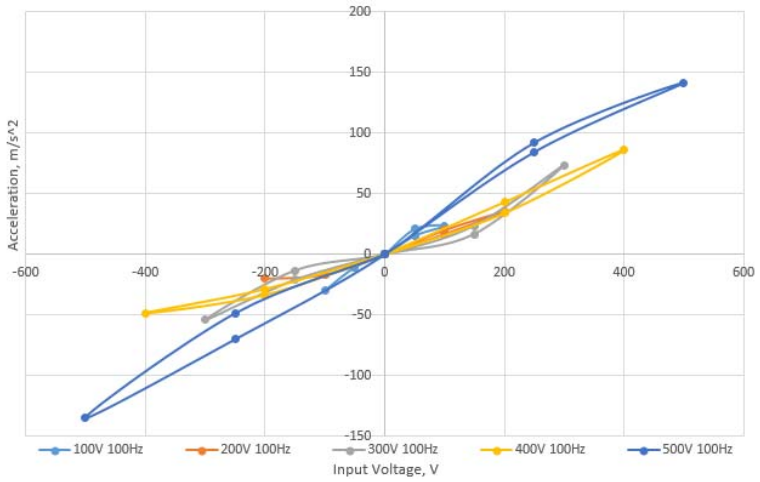

(a)

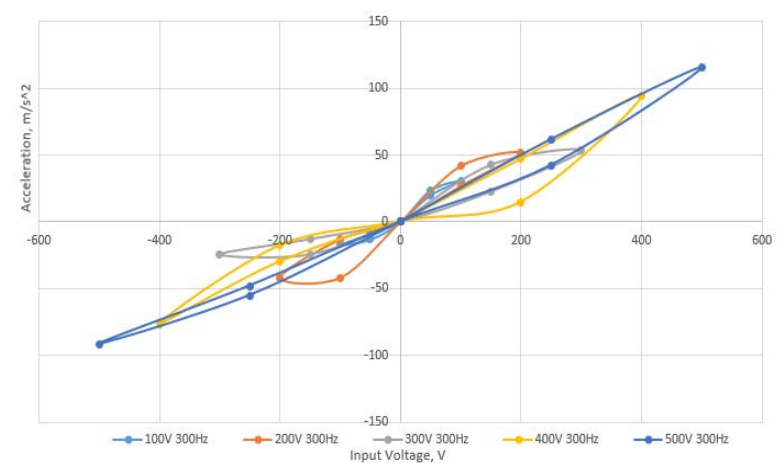

(c)

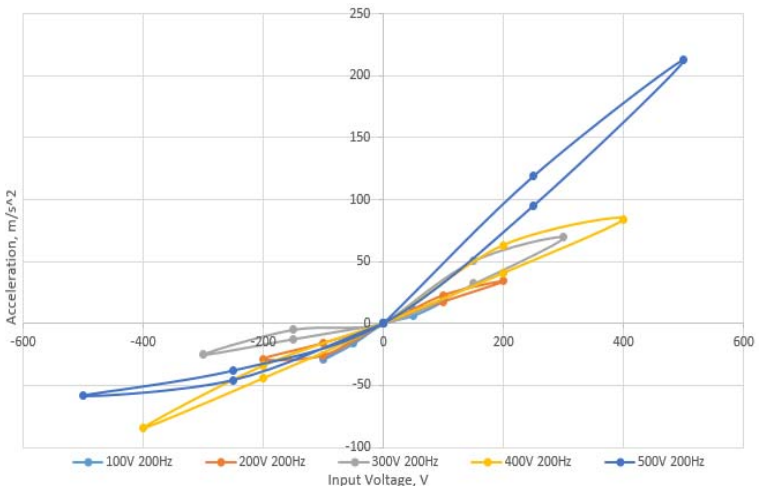

(b)

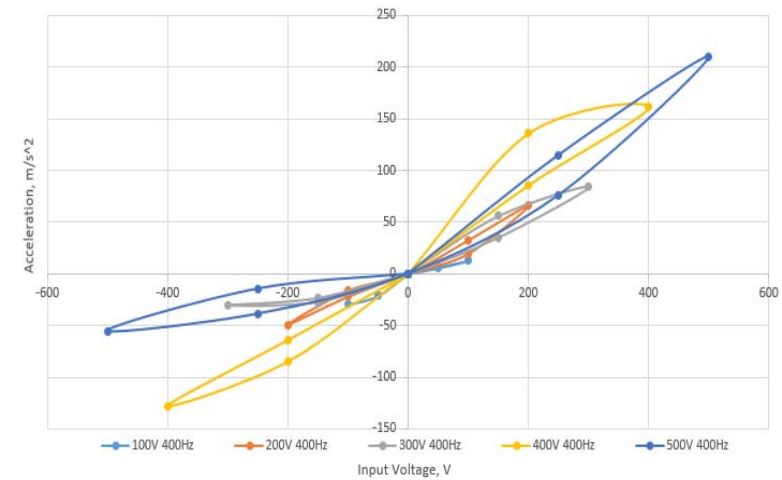

(d)

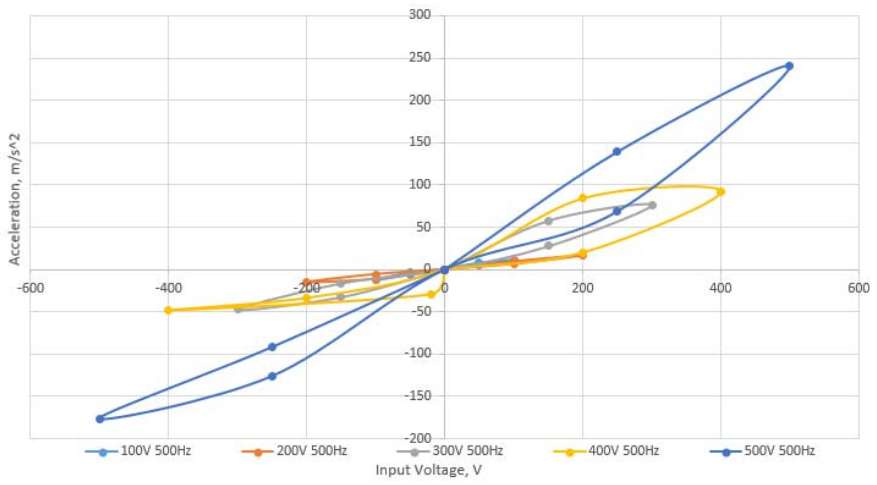

(e) 
Figure 7: Hysteresis effect of the piezoelectric patch actuator for frequency of (a) $100 \mathrm{~Hz}$ (b) $200 \mathrm{~Hz}$ (c) $300 \mathrm{~Hz}$ (d) $400 \mathrm{~Hz}$ and (e) $500 \mathrm{~Hz}$.

Similarly, for $200 \mathrm{~Hz}$, the area of hysteresis at frequency of $200 \mathrm{~Hz}$ enlarges constantly as shown in Figure 7(b). The maximum acceleration produced at $200 \mathrm{~Hz}$ is $212 \mathrm{~ms}^{-2}$, which higher compared to $100 \mathrm{~Hz}$ and $300 \mathrm{~Hz}$. This acceleration produced may explained by the second natural frequency of beam structure by referring to Figure 3, previously. At $300 \mathrm{~Hz}$ in Figure 7(c), the area of hysteresis is larger especially at positive input voltages. However, hysteresis curve started to see obvious when operate at higher than $200 \mathrm{~V}$.

For $400 \mathrm{~Hz}$ and $500 \mathrm{~Hz}$ in Figure 7(d) and Figure 7(e) respectively, the area of hysteresis is larger in positive input voltage which is similar as in Figure 7(c). In comparison, the hysteresis effect is expected to grow larger at $500 \mathrm{~Hz}$ compared to $400 \mathrm{~Hz}$. Both graphs are expectedly to be expanding with increasing of input voltages.

\section{CONCLUSION}

Throughout this study, the objectives are achieved to generate the dynamic responses of the coupled beam-piezoelectric structure using FEM model. The deflection, stress and strain analyses show significant discoveries in terms of maximum and minimum contours. The modal and transient analyses show that, the hysteresis affected the performance of piezoelectric. Thus, the correction algorithms or methods should be applied to improve the output produced by the piezoelectric actuator.

\section{ACKNOWLEDGEMENTS}

The authors would like to acknowledge Universiti Sains Malaysia and Kementerian Pengajian Tinggi for providing the financial assistance under Short-term and FRGS grants (304/PMEKANIK/60313052 and 203/PMEKANIK/6071370).

\section{REFERENCES}

[1] D. Damjanovic, Hysteresis in piezoelectric and ferroelectric materials, vol. 3. 2006.

[2] Y. Liu, J. Shan, U. Gabbert, and N. Qi, "Hysteresis and creep modeling and compensation for a piezoelectric actuator using a fractional-order Maxwell resistive capacitor approach," Smart Mater. Struct., vol. 22, no. 11, 2013.

[3] K. K. Leang and S. Devasia, "Design of hysteresis-compensating iterative learning control for piezo-positioners: Application to atomic force microscopes," Mechatronics, vol. 16, no. 3-4, pp. 141-158, 2006.

[4] G. Takács, Active Vibration Control Prototyping in Ansys: A Verification Experiment, vol. 19. 2011.

[5] M. S. Vijaya, "Piezoelectric Materials and Devices: Applications in Engineering and Medical Sciences,” vol. 186 pages, no. August, 2012.

[6] M. Imran, A. A. Abbasi, and M. J. Hyder, "Determination of modal characteristics of cantilever beam,” ICET 2016 - 2016 Int. Conf. Emerg. Technol., vol. 2, no. 2, pp. 4-6, 2017. 